\title{
- UNSEEING CHINATOWN: Universal Zoning, Planning Abstraction and Space of Difference
}

\author{
NAPONG TAO RUGKHAPAN
}

\begin{abstract}
The article investigates the technical rationality behind Bangkok's recent land use zoning plans. It does so through the example of Chinatown. The plans, intended to promote urban sustainability, introduce zoning techniques such as (1) land use subcategorization to hierarchize urban districts, and (2) density zoning to encourage intensive development around transit stations. The case of Chinatown foregrounds the discussion in this article, which then, in turn, explores the two zoning techniques. I argue that both techniques are formulated through a functionalist rationality, and thus omit place-specific conditions of land, such as local practices, histories and land tenure. Worse yet, the landed elite uses them to justify displacement and eviction. The article theorizes Chinatown as a space of difference, pointing to particularities that are unseen and thus at risk of being unmade by what is often passed off as technical expertise.
\end{abstract}

\section{Introduction}

One evening in the year 2012, my friend and I drove back from our dinner in Chinatown, a popular dining destination among Bangkok's middle class. As we drove along Charoen Krung Road, I noticed a long banner that had been put up across the width of two shophouses. On the long, thin piece of white cloth, in an angry font type, was written: 'This is Chinatown. We do not want the metro. Do not destroy'. I remember my near-reflex response that evening: I snorted and said to my friend, dismissively, 'Maybe the residents don't realize this yet, but once the construction is complete, they will profit from it'. I read the banner as yet another instance of NIMBYism against railinduced density. That reading coincided with my own professional philosophy at that time. Between 2009 and 2012, I was an urban planner for the Thai Department of Town and Country Planning. As a young, recently graduated planner trained in 'postmodern urbanism' (cf. Ellin, 1999), I was an advocate for 'density' and its companions (walkability, variety, vitality, placemaking, etc.). To me, density became a panacea for most if not all urban ills. Density was a word that I would put in every policy document I wrote.

My then unquestioned enthusiasm for density was shared by Bangkok Metropolitan Administration (BMA), the city government of Bangkok. In 2013, the BMA announced the latest zoning plan. Much anticipated by the public, the plan was believed to be a concerted response to the city's long entrenched problems of uncontrolled growth (see Figure 1a). In the 1980s and 1990s, Bangkok's land use policy (or rather the lack thereof) had consistently failed to keep up with national economic growth, the expansion of the middle class, the in-migration of labor from other provinces. The absence of a strong land use policy caused a regulatory vacuum that resulted in real estate-led suburbanization and industrialization of the urban fringes. Thus, it led to an explosion of metropolitan areas beyond Bangkok's administrative boundary into the surrounding provinces. The metropolitan form is large in extent but thin in density. The city's population density is too low to support an extensive, cost-effective public transportation. Cars are therefore chosen as a private solution to this very public problem. At this particular historical conjuncture, the BMA came to problematize low

\footnotetext{
This article is part of my doctoral dissertation research funded by Rackham International Research Awards. I wish to thank Jarunee Pimonsathean for pointing me towards important information, and Sirirutt Wongchanthajaroen for her excellent logistical assistance, friendship and support throughout my Bangkok fieldwork.
} 

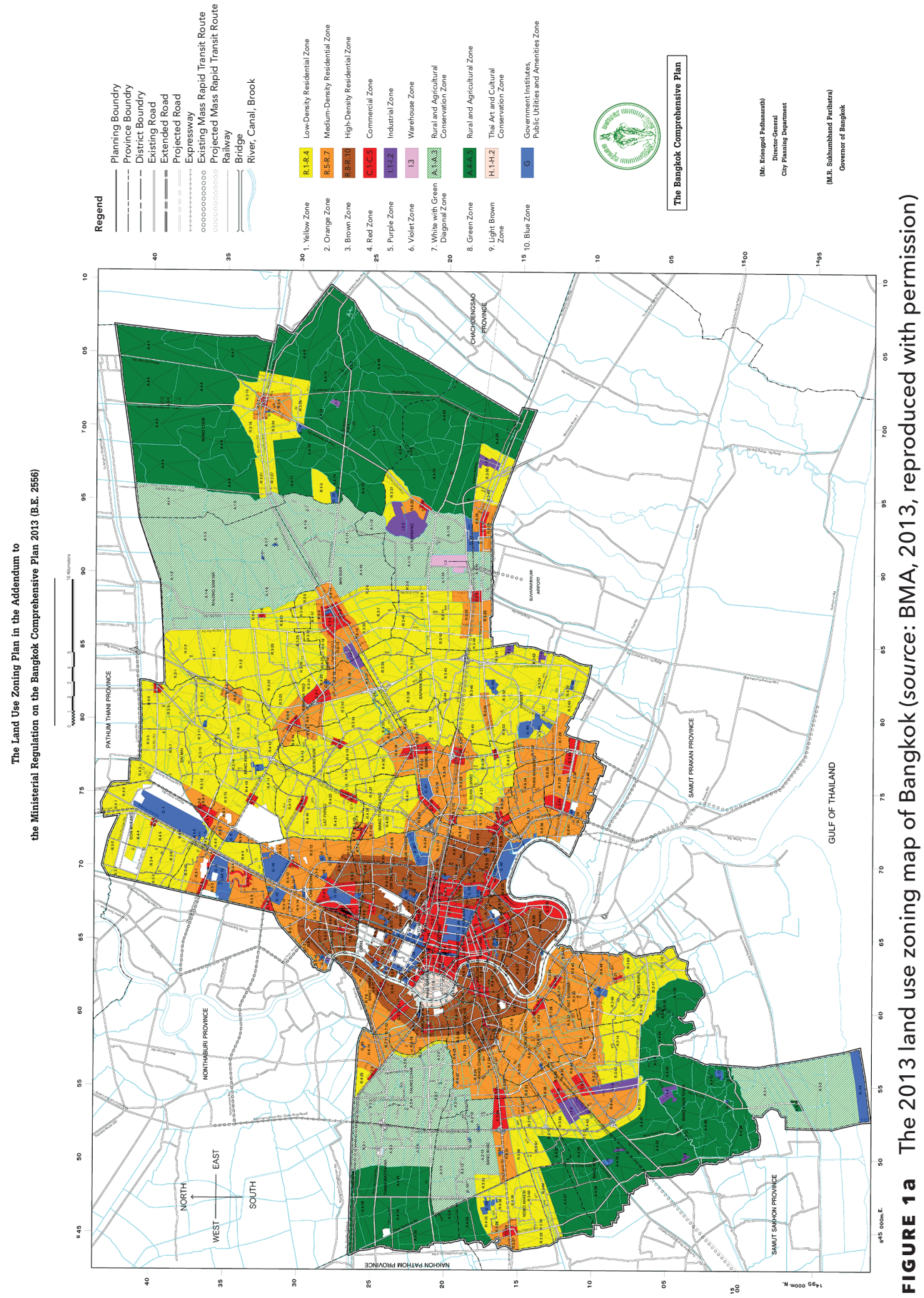


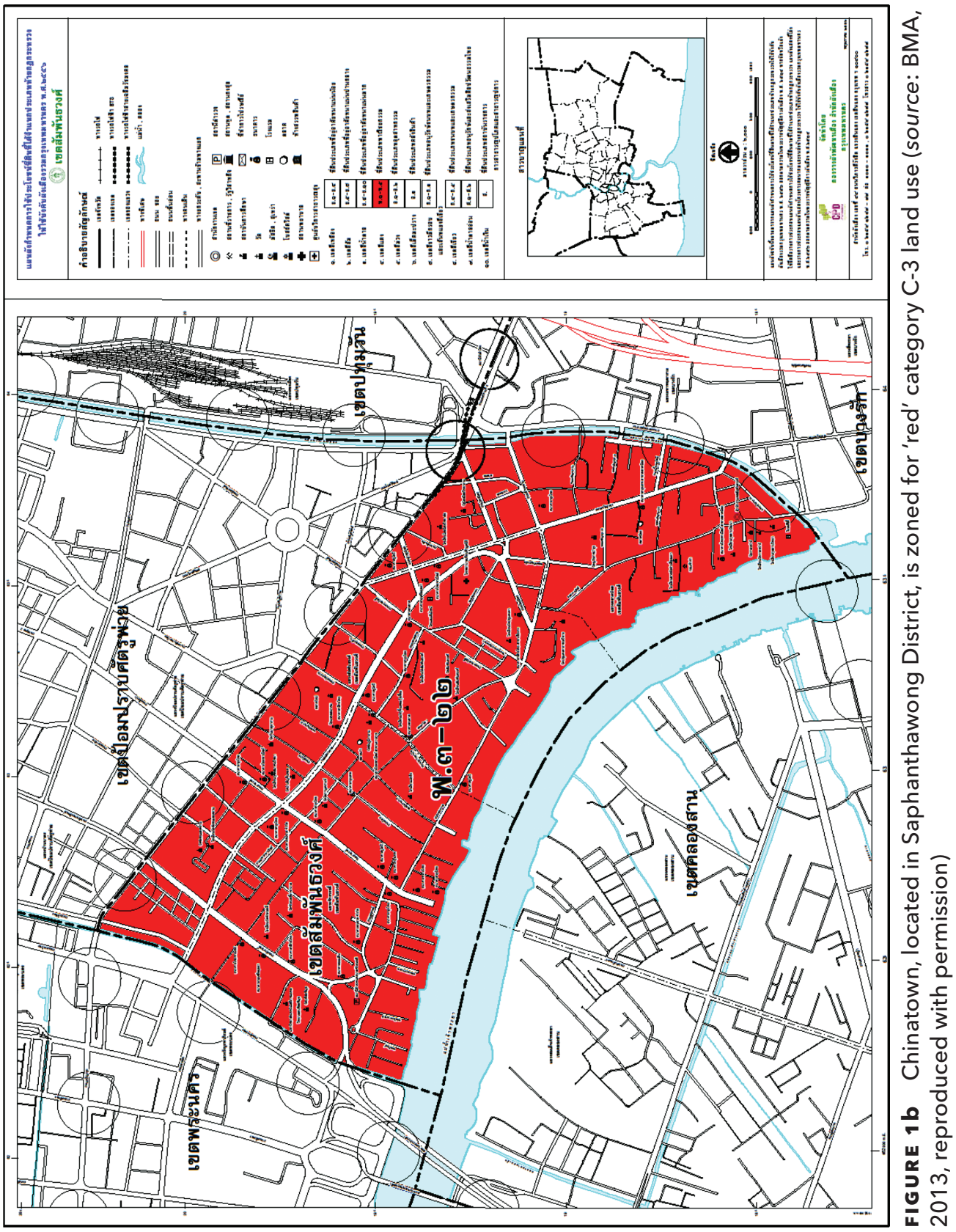


density as a culprit behind the fragmented urbanization. The 'compact city' - the city of walkable high-density zones-was seen as the solution.

Meanwhile, in Chinatown, eviction notices abound. Leases are shortened. In many cases, they are terminated. The landlords want to profit from the city allowing increased building density. However, unlike the familiar geographies of neighborhood change, gentrification and eviction (see Ghertner, 2014), the displacement dynamics here are not laissez-faire, but actively endorsed by the zoning regime. This requires us to re-evaluate the role of technical knowledge in validating state-sanctioned displacement. There is a rich scholarly literature on Chinatown, but one line of inquiry that pertains to this article is state intervention in the space of Chinatown. Anderson's important works $(1987 ; 1991)$ explore the state institutions and processes through which Vancouver's Chinatown was constructed, made and remade from 1857 to 1980. The author recounts the shift in dominant discourses, in which the state defined Chinatown according to its taste and interest. Chinatown shifted from an unsanitary, lowly place to a slum ripe for clearance, and on to a colorful, ethnic neighborhood. In a similar vein, Yeoh and Kong (1994) investigate changes in landscape meanings and state interventions of Singapore's Chinatown, which ranged from the modernist era, where progress was used to justify demolition, to the present-day postcolonial multiracialism, in which Chinatown constitutes one of the four racialized 'historic districts'. Lin (1998) examines how global forces-for example investment and capital flows-impact local development, communities and life in New York City's Chinatown. Although transnational in character, the dynamics are nonetheless mediated through local state actors and institutions. For example, the attempt to rezone Chinatown to accommodate a high-rise vision of Lower Manhattan was met with resistance (Lin, 1998: 151-56).

While the Chinatown-as-construction perspective above explores the making and remaking of Chinatown, in this article I consider the opposite question: I investigate how the particularities of Chinatown are unseen and risk being unmade by one specific state intervention: zoning. I theorize zoning as it is currently practiced in Bangkok as a technology of unseeing. The technology has many tools: height limits that only regulate individual buildings with little regard for the surrounding context, the geometry of transit density that only sees land in terms of density, and zoning categories that see land as land use. Therefore, instead of studying Chinatown as an ethnic settlement, I analyze Chinatown as a technical interface through which the ethnic settlement is intervened upon.

This article is a result of my fieldwork in Bangkok from January to April 2015. It draws on government documents such as present and past zoning plans, zoning standards, plan implementation manuals and planning petitions, interviews with government planners and Chinatown residents, and my attendance of various public meetings. It consists of six parts. In the second part, which follows, I outline two related theoretical perspectives that inform the analysis of this article. First of all, this part draws analytical inspiration from important writings on modernist zoning. I pay particular attention to how the state's intervention in the built environment often fails because intervention programs are produced through a limited technical rationality. Secondly, such techno-managerial rationality, although almost passé in the global North, is still a persistent and dominant mode of planning in the global South. Part three introduces Bangkok's recent zoning plans, which are often touted as the 'greenest' plans of Bangkok. They bring in, for the first time, new zoning techniques believed to promote urban sustainability. This third section explores two such zoning techniques-land use subcategorization and high-density zoning-and unpacks their technical formulation and rationality. The fourth part presents the case of Chinatown. I explore the experience of the two zoning techniques as they are implemented on the 
ground. In particular, I highlight a series of contestations that arise in response. These contestations expose the limits and flaws of the universal zoning techniques that do not account for the specific conditions of Chinatown. Parts five and six further theorize on universal zoning devices as they encounter a space of difference. Here, I discuss how universal zoning omits the 'space of difference', forgoing local practices and housing tenure. Conceived as a neutral, technical intervention, universal zoning does not have enough conceptual and ethical room to account for such conditions. Worse yet, it plays into the hands of the entrenched landed elite, who use zoning to enable eviction.

\section{Modernism, zoning and technical rationality}

Scholars have studied modernist urban planning in various geographical regions, highlighting its failure to improve urban conditions. The failure results from a narrow technical lens, a select way of seeing, through which urban planners view and intervene in urban space, whereby a complex phenomenon is reduced to a set of calculable variables and criteria. In his landmark book Seeing like a State (1998) Scott provides a detailed historical account of high modernism as a form of state intervention during the nineteenth and twentieth centuries. The high-modernist state project is characterized by simplified, utilitarian descriptions, a tendency to bring facts in line with representations, and a temporal focus on the future, on progress and on linear improvement. Most importantly, high modernism ignores history and devalues politics. It believes instead that rational thought, scientific laws and administrative criteria can provide a single answer. Technical knowledge is made superior to other sources of judgment. As a result, one inherent paradox-and one source of failure-is the fact that the social world is in flux. Twentieth-century modernist city planning, as a result of its scientific, ahistorical plan, clashes with deeply historical conditions. Despite planners' attempts to 'rule by the plan', the city resists being flattened to a set of numbers. Perhaps the greatest example is the city of Brasilia. Here, social engineering and spatial organization were brought into close alignment: the latter was believed to be facilitating the former (Holston, 1989). In particular, one quintessentially modernist tool was invoked in the project of organizing society: the master plan. The two-dimensional plan specifies, on a clean slate, physical elements such as housing units, recreational areas and public amenities. The clean slate hoped to produce a fresh, egalitarian landscape to neutralize class divisions and to 'replace the chaos of the capitalist city with a new, predictable, and controllable beginning' (ibid.: 58).

The modernist project is not limited to grand master plans exemplified by Le Corbusier's Plan Voisin (Scott, 1998) and Lucio Costa's Brasilia (Holston, 1989). In fact, the intervention can take various forms and often at smaller scales. In urban planning, intervention takes place more frequently in the minutiae of zoning, codes and ordinances than in wholesale redevelopment. And it is planning at the exacting 'genetic level' that significantly shapes the city form (Marshall, 2012; Talen, 2012). Zoning is a classic example of state modernist calculation. It is premised on the notion that land can be classified in terms of function. To this end, zoning instruments (for example, maps, diagrams, codes, taxonomy and classification) are deployed to first calculate space, and then to rule over it. Recent inquiry has helpfully paid attention to the role of 'calculation' used in the government's spatial intervention, exploring a variety of 'geographies of mathematization', that is, geographical, spatial implications of numbers and calculation. Government calculations can be both quantitative and qualitative (Crampton and Elden, 2006). Quantitative calculations include Cartesian geometry, numbers, counting or mathematization of the subject. Qualitative calculation can take the form of ranking, ordering or organizing a group. This article benefits from this line of inquiry. I shall investigate both the qualitative and quantitative zoning calculations used to intervene in the space of Bangkok's Chinatown. 
A few examples of zoning and mapping illustrate state calculations (and their limits). Mitchell's (2002) important work on colonial Egypt explores the technopolitics of land and natural resources. One such example is the cadastral map as a tool for colonial extraction of the country's agrarian land. The cadastral map is constructed for a certain purpose: tax collection. The objects in the map are drawn in a way that conveniently facilitated that purpose. However, unlike their represented form, the real shape of land plots is never perfectly geometric, much less rectangular. Mitchell terms this process 'reformatted knowledge', as technicians manipulate mapmaking through 'wilful interference' to produce a simple scheme of information to suit their purposes (ibid.: 106). Land is represented as a simple listing of information, such as ownership status and boundaries - that is, an itemization of quantifiable traits. Consequently, it dismisses the underpinning social relations, neglecting the broader agrarian transformations and the oft-contested histories behind that piece of land. As I show elsewhere (Rugkhapan, 2015), official mapmaking as willful inference can become willful violence when it chooses to see certain things and forego others. However, modernism has persisted long after colonialism. In the global South, Watson (2009a; 2009b) highlights the techno-managerial rationality, in which urban modernism still rules supreme. Importantly, the static blueprint conflicts with the indigenous pre-existing sociospatial relations. In her historical review of zoning in Durban, South Africa, during the apartheid and post-apartheid periods, Scott (2003) shows that modernist zoning maps were used to designate an industrial 'productive zone' imposed upon the town's indigenous residential landscape. Modernist in character, zoning acquired its power from the semblance of being scientific and neutral. It minimized the 'spatial unintelligibility', namely, the largely informal and mixed-use land, transforming it so that it 'eventually closely resembled the plans that were developed through the planning process' (ibid.: 258).

While modernist zoning is often associated with efficiency experiments, urban improvement and colonial exploitation during the nineteenth and early twentieth centuries, it intervenes in a different policy area in the twenty-first century: urban sustainability. Today, zoning and sustainability intersect. The former is believed to be a tool to promote the latter. For example, land use can be intensified to increase density. By manipulating zoning codes, it is believed, the city can be made more energy-efficient, less car-dependent and used intensively at its optimum (Charmes and Keil, 2015). Leffers and Ballamingie (2013) critique a series of recent intensification projects in Ottawa, Canada, showing how state institutions have been using zoning to discipline land towards the ideal of 'highest and best use'. The ideal is translated to specific zoning techniques such as upzoning, increased height allowance and brownfield redevelopment. In this formulation, the authors argue, the language of intensification, density and 'underdeveloped space' frames land as being simply about density, which prompts entrepreneurial subjects to think about land explicitly in terms of space optimization when, in reality, community concerns surrounding the issue of land development are more numerous. Although urban planning has shifted to embrace more 'postmodern' urban concerns such as density and walkability, or diversity and variety (Ellin, 1999; Fainstein, 2005), the legacies of modernist thinking, namely, faith in scientific judgment and authoritative solutions, have been ingrained in the way planning is implemented.

The modernist planning interventions outlined above, from Brasilia to Ottawa, from Egypt to South Africa, are formulated in terms of a particular rationality: a causal rationality of spatial intervention. There is a belief that we can govern spaces by first problematizing their conditions and then finding deterministic solutions for them. Huxley (2006) reminds us of the importance of, first and foremost, unpacking the governmental rationality-implicit and explicit-behind any spatial intervention. This methodology inspires part three of the article. She suggests we examine how 
certain 'truths' are produced and mobilized. Often, the underlying logic that connects 'problematization' and 'solution' is that there is a causal relation between space/environment and bodies/comportments-that is, there can be prescriptive, linear effects of space on subjectivities, assuming that space can shape comportments (ibid.: 774). In urban planning, causal rationality is exemplified by the belief that cities can and should be planned in particular ways in order to warrant desirable subjects, behaviors and spaces.

\section{Zoning for sustainability}

The 2013 zoning plan is the greenest plan of Bangkok. In it, the BMA substantially revised the ten Planning Objectives (POs) of the previous zoning plan, modifying these to convey environmentalist focus (see BMA, 2006: 3; 2013: 2-3). In what I call the greening of POs, the BMA made a stronger connection between each PO and its urban environmental implications (see Table 1). For example, an emphasis on convenience and efficiency is added to the Transportation PO; job-housing balance and travel-trip reduction was added to the Housing PO; environment-friendly industries were included in the Manufacturing PO; urban growth management and compactness were added to the Agriculture PO. Moreover, two new POs, 11 and 12, were added. These two new objectives-the objective on natural disasters and the objective on global warming-similarly point to the explicit environmental policy concern of the latest zoning plan. With these sustainability vocabularies permeating its production, the 2013 zoning plan is clearly environmentalist, suggesting the city's new awareness of and commitment to the broader global agenda of urban sustainability (BMA, 2013: 2-3).

We understand discourse by studying its enactment. Thus, if the aforementioned POs attest to the vision that underwrites the new zoning plan, zoning techniques are prescribed to realize such a vision. This article focuses, in turn, on two zoning techniques and their underlying rationality. First, I investigate the government's attempt to segregate land in terms of its functional land use category, for example, commercial, residential or industrial. Each category is further subdivided or subcategorized to reflect the position of a given zone within the city's larger hierarchy. Second, I discuss the BMA's experiment with a fashionable planning idea-transit-oriented development (TOD). The city government wants to make TODs sprout up by 'upzoning'-by increasing density around every metro station.

TAB LE 1 The 'greening' of Planning Objectives

\begin{tabular}{lll} 
Planning Objective & 2006 Zoning Plan & 2013 Zoning Plan \\
\hline $\begin{array}{l}\text { Planning Objective 5 } \\
\text { (Transportation) }\end{array}$ & $\begin{array}{l}\text { Support mass transit and connect } \\
\text { transportation networks }\end{array}$ & $\begin{array}{l}\text { Support convenience, speed, and safety by } \\
\text { developing and connecting mass transit and } \\
\text { transportation networks. }\end{array}$ \\
\hline $\begin{array}{l}\text { Planning Objective 6 } \\
\text { (Housing) }\end{array}$ & $\begin{array}{l}\text { Improve and rehabilitate } \\
\text { residential areas and urban } \\
\text { centers }\end{array}$ & $\begin{array}{l}\text { Improve job and housing balance in order to reduce } \\
\text { trips by improving and rehabilitating inner-city } \\
\text { residential areas and developing suburban centers }\end{array}$ \\
\hline $\begin{array}{l}\text { Planning Objective 7 } \\
\text { (Manufacturing) }\end{array}$ & $\begin{array}{l}\text { Support high-skill, high-tech } \\
\text { industries that are safe and free } \\
\text { of pollution }\end{array}$ & $\begin{array}{l}\text { Support manufacturing industries that do not } \\
\text { affect urban environment, and high-skill, high-tech } \\
\text { industries that are safe and free of pollution }\end{array}$ \\
\hline $\begin{array}{l}\text { Planning Objective 8 } \\
\text { (Agriculture) }\end{array}$ & Retain farmland & $\begin{array}{l}\text { Retain farmland through compact urban } \\
\text { development and growth management }\end{array}$ \\
\hline $\begin{array}{l}\text { Planning Objective 11 } \\
\text { (Disaster management) }\end{array}$ & - & $\begin{array}{l}\text { Protect human safety against natural and manmade } \\
\text { disasters }\end{array}$ \\
\hline $\begin{array}{l}\text { Planning Objective 12 } \\
\text { (Global warming) }\end{array}$ & - & $\begin{array}{l}\text { Address global warming by reducing energy use and } \\
\text { increasing green space to reduce carbon emissions }\end{array}$ \\
\hline
\end{tabular}




\section{- $\quad$ Land use subcategories}

Issued in 1992 and 1999, respectively, the first two zoning plans of Bangkok were rather crude. The taxonomy of land use categories was limited to a few basic categories, such as residential, commercial and industrial (BMA, 1992; 1999). For example, in the first zoning plan for Bangkok issued in 1992, a total of 62 areas were zoned as 'commercial' (BMA, 1992). This simplified plan did not distinguish scale. The regulations for the 62 zones were the same, despite remarkable differences in size and character. The BMA adopted this simplified scheme from the Department of Town and Country Planning, Thailand's national agency for planning. However, the national standards intended for Thai towns and cities proved to be too coarse for the capital city. ${ }^{1}$ In preparation for the third zoning map of 2006, then, the BMA commissioned a study for new planning standards. It tailored these to better suit Bangkok's land use, which had grown increasingly complex over the past few decades (BMA, 2005).

A major addition was a scheme to subcategorize each land use zone. Subcategorization is a device for fine-tuning the land use plan to existing land use types. The example below illustrates the subcategorization of ' $\mathrm{C}$ ' or 'commercial' land use zones (BMA, 2013: 4-5):

- C-1: small, suburban commercial centers (general residential suburban areas)

- C-2: suburban centers of business, housing and employment (potential suburban growth areas)

- $\quad$ C-3: general central business districts (CBDs)

- C-4: sub-central business districts around major rail nodes (park-and-ride areas)

- C-5: regional and international commercial centers.

Land use subcategorization is formulated under a particular logic: scalar thinking. The classification of land into land use classes is part of functionalist thought. Land is, first and foremost, assumed to be functional. A given zone is supposed to have an identifiable function-residential, commercial, industrial-and to duly perform that designated function. Secondly, the subcategorization of zones as, for example, C-1, C-2 or C-3 is not only functionalist, but also scalar. It is a hierarchical way of organizing the city. The subcategorized zone reflects its role vis-à-vis the city (BMA, 2005: 5-99). In this manner, the C-1 zone, the suburban commercial center, caters for the day-to-day basic provision of goods and services in the suburbs. C-2 functions as a larger suburban area with a more diverse range of commercial services. C-3 is a CBD, catering not only for its immediate communities but also for the city's residents at large. C- 4 acts as a park-and-ride node that supports the economic functions of the areas around the major rail stations. And finally, C-5 is Bangkok's downtown core. The same logic applies to other land use classes. For example, residential zones are subcategorized according to density as low-density, medium-density and high-density.

Subcategorization as a device, I argue, is an attempt to produce functional analogues across the city. Currently, the zoning map designates $20 \mathrm{C}-1$ zones, 5 C-2 zones, $43 \mathrm{C}-3$ zones, $5 \mathrm{C}-4$ zones and $7 \mathrm{C}-5$ zones, which are distributed around Bangkok (see Figure 1a). From the city planners' point of view, since these areas perform similar commercial functions, they are treated as analogous and regarded as perfectly identical. For example, a suburb on the city's northern fringe and, say, its southern counterpart are viewed as analogous C-1 zones because, in terms of function, they both act as suburban commercial centers. Likewise, two highly trafficked districts are viewed as comparable CBDs or C-3 zones if they function like one (that is, they are large enough to cater for a wide array of goods and services). Moreover, since these zones are viewed 


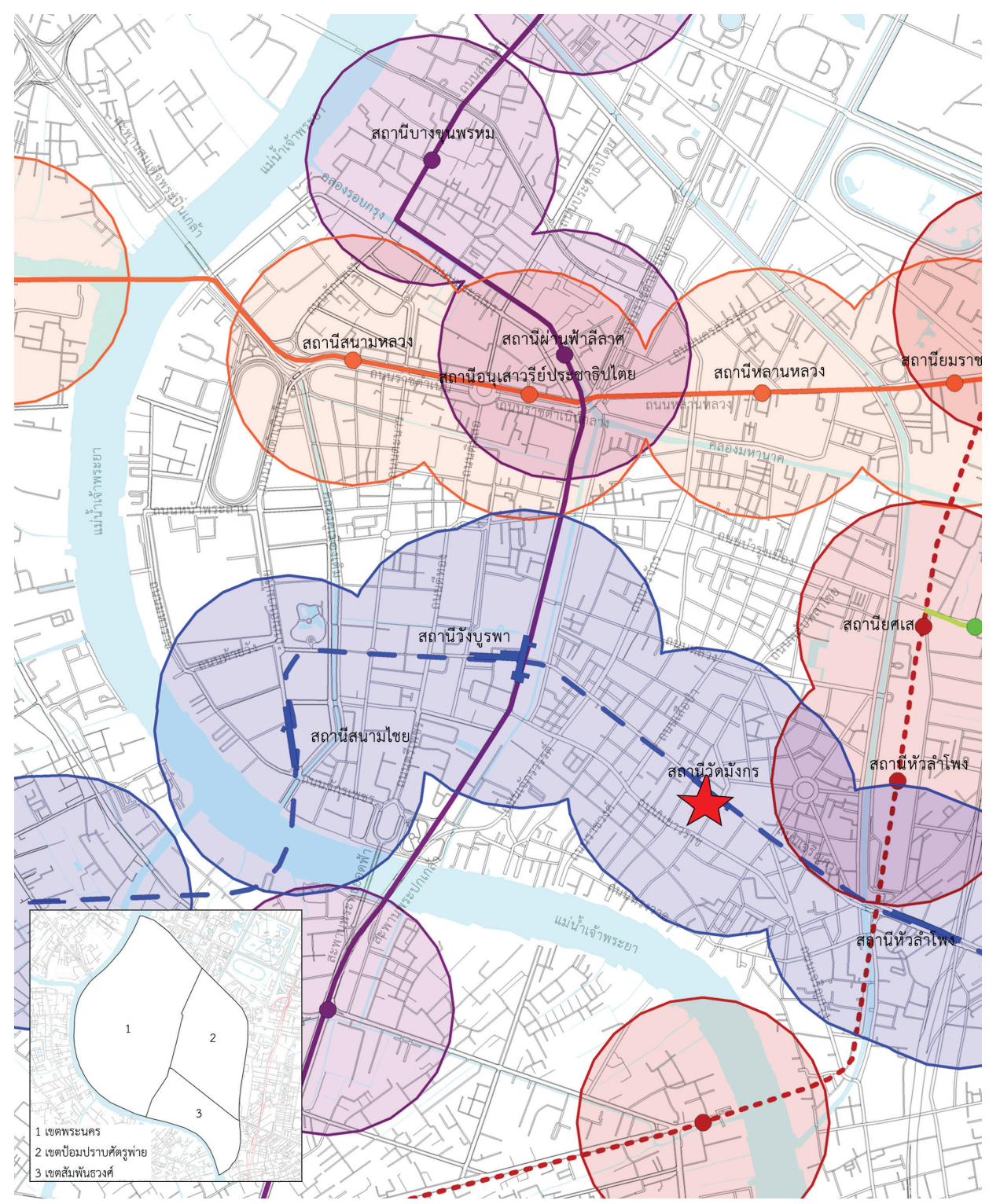

FIGURE 2 Illustration of the proposed 500-meter radii of density upzoning around future transit stations; the star marks the location of Chinatown station (source: TURCl, 2015)

as analogous, they are thought be governable by the same regulations. The zoning plan, then, proceeds to prescribe an identical set of zoning requirements (for example, permissible and prohibited land use activities; height and development intensity).

- $\quad$ Zoning for transit-oriented development (TOD)

The second addition to Bangkok's zoning is upzoning: an increased density for areas surrounding transit stations. Motivated by the concept of transit-oriented development (TOD) popularized in Western cities to promote compact urbanism (Cervero et al., 2002), the BMA, too, has adopted the concept rather enthusiastically as a potential 

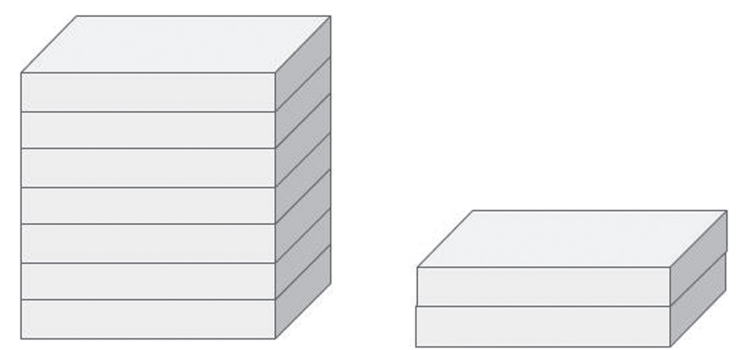

FIGURE 3 Illustration of a FAR (floor-area ratio) of 7:1 and a FAR of 2:1 (assuming a building coverage ratio of 1:1) (source: author's rendition)

cure for the city's urbanization problems. I locate Bangkok's newfound preference for 'urban density' in two contexts. One is the historical-domestic context of the city's long-entrenched urbanization problems. The other is the contemporary-international policy climate of urban sustainability. The latter, city planners hope, will help cure the former. In line with the revised POs, the adoption of TOD aims at forging more dense and compact urban development-an urban form that is internationally praised for its promising potential to contain sprawl.

Density is thus seen as a vehicle for achieving compact urban form, as an enabling techne (Legg, 2006; 2007) that can direct people towards where they should live and work: the transit node. In particular, the preparation of the zoning plans of 2006 and 2013 coincided with the expansion of Bangkok's metro lines. Therefore, the vision of railbased city life seemed particularly alluring. The planners of the zoning maps responded quite enthusiastically to this vision. Their faith in density (on a conceptual level) was thus translated on a technical level into one particular zoning technique: that of increased density around transit stations to forge the emergence of a TOD node. Development projects-residential, commercial or office space-with a total floor area of over 10,000 square meters is now permissible, if not encouraged, on condition that the development be located within a 500-meter radius of a metro station. Land parcels within the 500-meter radius are now appraised as being walkable. These are deemed appropriate to accommodate growth and are thus upzoned for more intensive use (see Figure 3). Conceived in this manner, the zoning map is therefore a tool of visibility (Legg, 2006; 2007): it makes the land surrounding a transit station on the map visible in terms of land use density. In turn, density became a numerical value that could be increased, decreased or arithmetically manipulated at will.

The technical rationality that underpins Bangkok's enthusiastic adoption of the TOD zoning is the belief that walkable environments will lead to fewer car trips. Following Huxley (2006), I propose that the assumed causal connection between the TOD zoning and car dependence needs systematic dissecting. First, the geometry of a 500-meter radius is designated a 'walkable' distance. Buildings and activities within the 500-meter radius, the reasoning goes, are accessible from the transit station. By upzoning or increasing the development density around the metro station on the zoning map, planners can therefore create a canvas that is conducive to creating walkable, mixed-use environments that will, in turn, allow people to live, work and play therein. As a result, there will be less need for cars, since people can rely on the conveniently located transit stop as their main means of transportation and on nearby facilities as destinations in themselves. It is in this cause-effect reasoning that TOD zoning has been inserted into Bangkok's zoning maps. The logic behind Bangkok's TOD zoning is one of spatial causality, whereby space, if properly governed, is able to direct a certain desired behavioral outcome. 


\section{Unseeing Chinatown}

What is the experience of the two zoning techniques-land use subcategorization and TOD zoning-when they are translated on the ground? In this section I use Chinatown as an interface of policy translation (Watson, 2009b) - the arena in which the technical plan is put into practice. As will be shown, the interface opens up the space of Chinatown as a site of technocratic struggle. By way of introduction, Chinatown is zoned as C-3 (major central business district) (see Figure $1 \mathrm{~b}$ ). The stipulated floor-toarea ratio (FAR) is 7:1, meaning that the allowable total of a given building's developable floor space is seven times that of the plot on which the building stands. By comparison, the highest FAR for zone C-5, Bangkok's downtown core, is 10:1 (BMA, 2013). Also, a new metro station is under construction near Wat Mangkon, a famous Chinese shrine located in the heart of Charoen Krung Road, one of the oldest Chinese areas of Bangkok. Therefore, TOD zoning applies to the areas within a 500-meter radius of Wat Mangkon metro station (see Figure 3). In the next subsection I discuss these two zoning techniques and their impact on the space of Chinatown.

\section{- $\quad$ Chinatown as a land use subcategory}

In formulating a land use subcategory, the BMA selected one "prototypical district' to represent the other districts in that subcategory (BMA, 2005). For subcategory C-3, Samyan was selected as the prototype to represent Bangkok's other CBDs. Founded in the 1960s, Samyan is a market neighborhood comprising commercial blocks located close to Chulalongkorn University, its main driver of growth. Samyan is a commercial and mixed-use district. It is characterized by various types of trade, ranging from wet markets to used auto parts. For the purposes of Bangkok's planning standards, Samyan was profiled in terms of its function-existing land use types, population density and building dimensions such as building use, height and FAR. These numbers were drawn out and tabulated to portray the functional character of Samyan. In turn, Samyan is no longer an urban district in itself. Rather, Samyan has been abstracted to a statistical figure. This abstract figure, in turn, represents the other functionally equivalent C-3 zones.

Does the label C-3 represent the experience of Chinatown, commercial or otherwise? Certainly, designating Chinatown as commercial is sound, if not commonsensical. Indeed, Chinatown has always been a major trading district of Bangkok since its early history in the late eighteenth century. Today, Chinatown is the site of various retail and wholesale businesses, cottage industries, restaurants and food outlets. Goods and services in Chinatown range from gold shops to textile stores, from auto repair services to rice storage godowns. Thus, in terms of land use, Chinatown is certainly commercial in character. Also, in terms of its role vis-à-vis the city, Chinatown firmly constitutes one of Bangkok's many CBDs or C-3 zones, as it caters for both district-level and city-level residents.

However, there are at least two problems with the conception of the subcategory C-3: limits of generalization and standardization, and severe omission of its history. Let us recall that subcategory C-3 is a standardized figure based on (1) the daytime population of the area (labor in the trade and business sector) and (2) its extrapolated projection (BMA, 2005: 5-103). Chinatown is a counterargument to these calculations.

First, the daytime labor population ignores 'other populations' such as tourists and migrant workers who occupy the space of Chinatown, traversing it throughout the day. The static daytime population does not account for these populations, which may well be transient, yet are instrumental in bringing about the spatial qualities of the 'bustling, chaotic Chinatown', which make it differ markedly from its prototype, Samyan, and other C-3 business zones. Chinatown is the second most dense district of Bangkok. 
Its population density of 18,615 people per square kilometer is substantially larger than that of other C-3 zones, such as Pathumwan (6,160 people per square kilometer) and Bang Khen (4,526 people per square kilometer) (BMA, 2014a: 4). Moreover, the daytime population makes a temporal assumption about the zone, consigning a certain space to a certain time. For example, commercial zones C-1 to C-5 calculations are all based on these zones' daytime populations. This suggests the role of the zone as employment sites for labor and workers during the day. By contrast, residential zones R-1 to R-10 use figures for night-time populations, assuming that these zones are places of residence after work. However, unlike many other C-3 business districts that die down after working hours, night-time Chinatown takes on a different profile. At night, Chinatown is characterized by small eateries, sidewalk vendors, pedestrians and tourists, who start taking over Yaowarat, the main artery of Chinatown, as night falls. Chinatown shifts from a daytime place of trade and commerce to a more leisurely nighttime district. It is this shift, this ebb and flow of population, that is omitted in the current categorization.

Second, flawed technical generalization aside, a more serious issue is the omission of, and disrespect for, the area's history. There is a whole commercial history of Chinatown that the 'commercial zone', at best, fails to fully consider or, at worst, misrepresents. One important question arises here: are two similarly designated zones really comparable or 'analogous', as the zoning map seeks to suggest-that is, do all of the 43 C-3 zones, which include Samyan, the 200-year-old Chinatown, the moderndowntown Sukhumvit and the eastern subcenter of Bang Kapi, to name a few, share similarities, functional or otherwise? Chinatown is an old district. By the eighteenth century, Chinese traders had settled in what is modern-day Bangkok, occupying the swampy areas east of the Chao Phraya River (Skinner, 1957; Nǣngnō i Saksī, 1991; Sirikulchayanont, 2009). In the wake of trade liberalization in the mid-nineteenth century, modern streets were constructed. The streets later became the locus of immigrant Chinese urban space. In this part of Bangkok, Chinese commercial practices are reflected in the built environment: the rice godowns, the Chinese shrines, the shops, as well the medical clinics and dispensaries. This is by no means an exhaustive review of Chinese immigrant history: suffice it to say that place-specific practices produce place-specific typologies. As I shall show below, this 'difference' provides a basis for contesting the zoning map.

The FAR allowance is a case in point. The zoning plan stipulates a FAR factor of seven for all the CBDs (BMA, 2013: 41) (see Figure 4). Again, the intention is to upzone or to promote density. However, the floor space allowance contrasts dramatically with existing settlement patterns and building typologies (see Figure 5). Rather than a Western-style CBD filled with tall office blocks, the 'commercial' nature of Chinatown takes on a different physical form. Chinatown is a low-rise district characterized by two- to four-story shophouses (see Figures $5 \mathrm{a}$ to $5 \mathrm{~d}$ ). Therefore, the existing FAR factor ranges between 1.03 to 3.91. For example, the neighborhoods of Charoen Chai and Woeng Nakhonkhasem have a current FAR factor of 2.19 and 2.04, respectively (Pimonsathean, 2009; TURCI, 2015: 1-45). In fact, as an old district, Chinatown is mostly built up. Its building density has changed very little in the past decade. One BMA-commissioned survey, conducted 15 years ago, reports an average FAR of 2.02 (KMITL, 2001, Chapter 4: 3). In my archival search through recent planning applications, I found that, between 2010 and 2014, the District Office processed approximately 8 to 24 building permit applications per year, and almost all of these applications were for two- to four-story buildings. ${ }^{2}$ Therefore, in order to fulfill the universal vision of a C-3 CBD, the desired FAR factor of seven presumes a

2 Records of Building Construction Permits, Public Works Division, Saphanthawong District Office, 2010-2014; in these years, applications were received for 3 three-story, 36 two-story, 55 three-story, 34 four-story, and three fivestory buildings. 


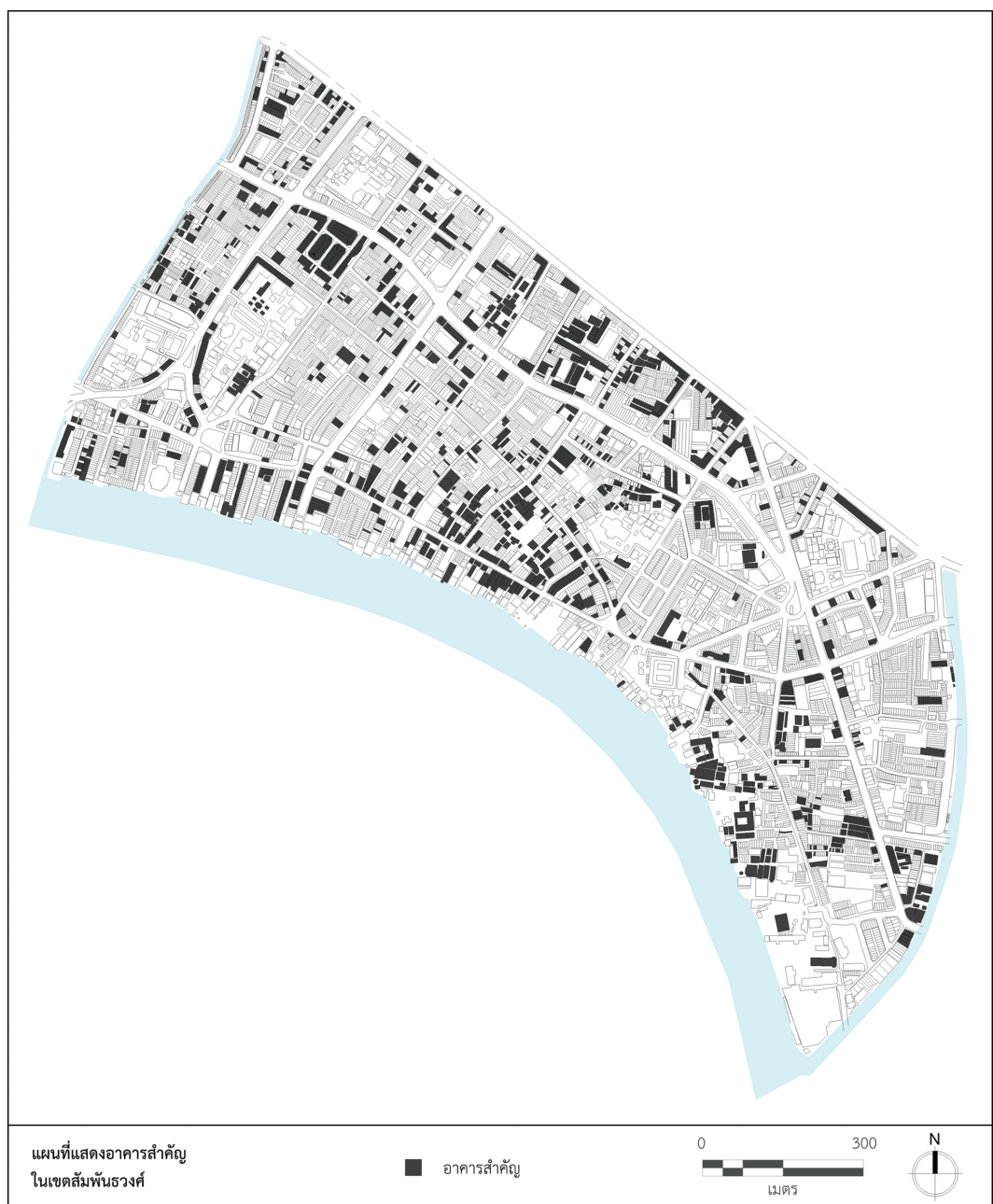

FIGURE 4 Settlement patterns in Chinatown; the darker shading represents significant buildings, identified as having potential heritage value (source: TURCl, 2015)

demolish-then-redevelop approach to current building stock. As I will show below, the approach favors the landlord.

Contestations arose: residents felt that the abstract C-3 label did not reflect their version of reality. In 2012, two Chinatown communities submitted petition cases, and their letters illuminate the nature of the contestation. The first was Charoen Chai, an old Chinese neighborhood on Charoen Krung Road. In their motion letter, signed by 42 residents, Charoen Chai petitioned that its zoning color be changed from 'red' to 'light-brown', or from 'commercial' to 'historic preservation' land use. ${ }^{3}$ The motion explains the long history of their settlement. In particular, they call attention to the old buildings, which date back to the reign of King Rama V (1868-1910). These buildings, they argue, are of historical and architectural value, and should actually be protected under the National Act on Ancient Monuments. To support the claim, the movants enclosed a hand-drawn cadastral map documenting the age of each building in the 

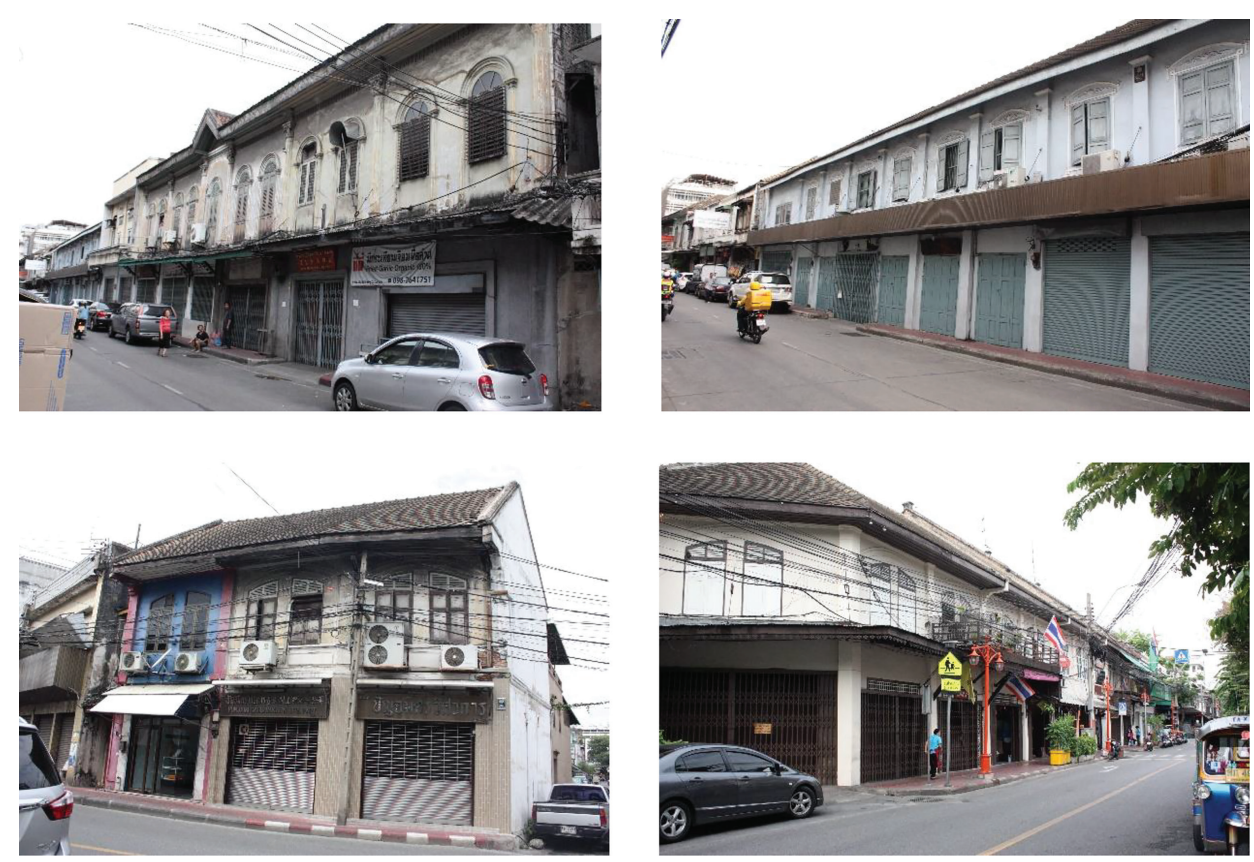

FIGURE 5 These four photographs show the two main characteristics of building typologies in Chinatown: (1) they are low-rise and (2) built in a row (photos by the author)

neighborhood as part of their plea for serious reconsideration. The movants thus used the age of buildings as evidence to add weight to their appeal, establishing detail in the face of a comprehensive plan that lacked fine-grained resolution. Another Chinatown neighborhood, Weong Nakhonkhasem, submitted a similar motion to the BMA, calling for change from 'commercial land use' to 'commercial land use with historic significance'. The movants also demanded that the FAR factor be reduced. ${ }^{4}$ Their motion claimed that the high FAR factor ignored the historical value of the district, which dates back to the reign of King Rama V (1868-1910). Worse yet, the FAR incentivized speculation and land grabbing. The movants also argued that once it came into effect, the new zoning plan would 'open up opportunities for demolition, accelerating the rapid disappearance of the nation's historical roots'.

The BMA dismissed both motions. In the preamble, the planners did acknowledge the historical and architectural value of both Charoen Chai and Weong Nakhonkhasem. They acknowledged that the two communities are nationally famous, historical commercial districts that should be 'commemorated as national heritage for later generations to study and take pride in'. Yet, as tenement housing, the BMA argued, the rental buildings had been left 'dilapidated due to lack of care'. ${ }^{6}$ The BMA proceeded to dismiss the motions on two grounds. First, the two areas functioned as 'commercial zones catering for city-level services, and have high population densities', and have always been 'zoned commercial in the previous zoning plans'. ' Second, the Building Ordinance of 1999, the BMA suggested, was already in place to protect and control

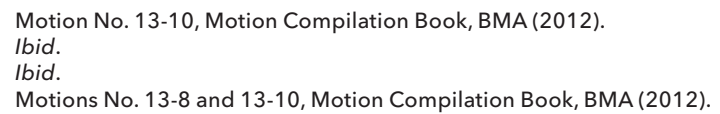


building height within the areas: 16 meters around temples, and 37 meters for the rest of the areas. The decisions, although made separately for each motion, invoked the same rationale and cited the same legal precedents. I will come back to critically discuss both in part five. For now, these decisions were upheld by the Planning Advisory Board without further comment. ${ }^{8}$ The residents obviously lamented the decisions. Although historical preservation is listed high as one of the official POs in the zoning map (PO 9), one resident contests that zoning only 'preserves' what it designates 'historic preservation land use', namely, Rattanakosin Island, the only historic preservation zone in the entire city of Bangkok (see Figure 1b). Therefore, the official definition of 'historic preservation', she argues, is severely inadequate, because it is too narrowly defined around one historical district, ejecting 'other [historical] parts that have made up the city' from official preservation concerns. ${ }^{9}$

\section{- $\quad$ Chinatown as a calculable density}

If the C-3 label is an abstract category, the 500-meter TOD zoning is an abstract geometry. Unlike the actual construction of the metro station, for which a preliminary engineering survey had to be conducted to determine its feasibility, no survey was conducted for the walkable areas surrounding each of the stations. Instead, it was assumed. The assumed radius of walkability was rationalized on the basis of the Planning Department's GIS map. This meant that a circle is drawn, quite literally, around every metro station platform to designate the zone of walkability and thus determine the higher-density areas (see Figure 3). Similarly, the map is also used for planning interpretation (BMA, 2014b). To determine whether or not a given structure lies within the radius, the circular extent of the walkable radius is to be strictly calculated on the basis of the official GIS interface alone. The BMA requires that the distance between a building and the metro station be measured only on the official construction blueprint of each metro station, not from the actual site itself, or from the actual experience of walking to the metro station (BMA, 2014a). The planners measure a location based on its numerical length from the station, thus alienating other experiential qualities of the walkable TOD that they seek to promote in the first place.

The TOD zoning caused quite a ripple across Bangkok's real-estate market. With a higher developable density comes a higher land price. In anticipation of the 2013 zoning map, land speculation around current and future metro stations skyrocketed as investors, real estate agents and owners sought to capitalize on their now prime locations. In Chinatown, the 500-meter TOD zoning has led to a series of eviction cases and shortened leases. Motivated by the new prospects of profitable development, landlords want to turn their properties into high-density developments or sell their titles to other developers. They have already begun, quite abruptly and in many cases without prior notice, to shorten lease periods from three years to one year, and recently to month-bymonth, or have terminated leases altogether. ${ }^{10}$

The TOD zoning is being strongly contested by the residents of Chinatown, who, as tenants of their current residences, fear that the zoning provisions will result in demolition and evictions, thus undermining their housing security. The residents criticize this looming threat on their areas, asserting that planners did not see their area's historic significance. The most vocal critics are from the neighborhood of Charoen Chai, which is located right around the upcoming metro station. Here, I will briefly describe their narrative of contention. Residents' main contention is planners'

$8 \quad$ Ibid.; ibid.

9 Comments raised at the public forum Rue mueangkao rakngao rao cha yu trong nai [Demolishing the Old Town, where will our historical roots be?], Bangkok, 5 August 2012.

10 Based on an article in the Bangkok Post by P. Atthakor, published on 2 November 2012), entitled 'Preservation pleas falling on deaf ears', available at http://www.bangkokpost.com (accessed 18 May 2015). 
ignorance of the neighborhood's spatial history in at least three aspects: formation history, collective identity and trade patterns. As an old neighborhood that has existed for over one hundred years, Charoen Chai has been home to four or five generations of Thai Chinese families. Its historical, cultural and architectural heritage can be traced back to the economy of Charoen Krung Road, the first modern street built in Bangkok after the mid-nineteenth-century trade liberalization. Upon completion of the road in 1864, shophouses were built to accommodate a modern form of trade. Soon after this, at least five Chinese shrines were built around the Charoen Chai neighborhood. These shrines were, and still are, the center of Chinese spiritual life overseas and represents the epitome of Chinese collective identity. ${ }^{11}$ Chinese spiritual life extended far beyond a religious space: it is also a space of social gathering, self-help and Chinese medical care, as at this time such basic needs were extremely short supply for early Chinese immigrants. Owing to the proximity to the shrines, the neighborhood of Charoen Chai developed a particular kind of space: an agglomeration of Chinese ritual-merchandise stores and small eating houses. In what economists call agglomeration economies, Charoen Chai boasts the largest of its kind in Thailand. Here Thais of Chinese descent can find all sorts of products that celebrate Chinese rites of passage 'from birth to death', some of which can no longer even be found in China itself after the Cultural Revolution. ${ }^{12}$ Similarly, like most Chinatowns in Southeast Asia (Jackson, 1975), the dense concentration of eateries are a relic of Chinatown's past as a site of constant, laborintensive activities. This is exemplified by the well-known 'laborer's noodle shop', ${ }^{13}$ a popular spot among Bangkok food pilgrims, named for its cheap prices and the large portions that were served to the Chinese laborers of the past. Another example is the old building of a well-respected Chinese physician, which bears the name Sow $L i$ and is located a few steps from the metro station. In Teochew Chinese, sow means to help, and li means people or the masses. Thus its name refers back to the public-health conditions of the time and to the shortage of medical care for Chinese immigrants (CCRG, nd). This reconstructed and somewhat romantic account reflects a spatial history that emerged from the symbiotic relationship between Charoen Chai and its surrounding economies.

However, despite their elaborate narrative, Charoen Chai residents have seen their local history denied. In its dismissal of the residents' petition to revoke the 500meter density provisions, the BMA claims that the Building Ordinance of 1999 is already in place to restrict building height to 37 meters, suggesting that this Ordinance prohibits overly high buildings. However, I want to highlight that while a large-scale project of over 10,000 square meters cannot take the form of a tall, vertical structure, it may very well be built horizontally. Thus, instead of building a high-rise building of 10,000 square meters, the landowners could build a low-rise structure by redeveloping adjacent plots into one big project. This is where the unintended politics of technical rationality comes in. The 500-meter radius conveniently plays into the hands of Chinatown landlords who tend to already possess a large number of contiguous land parcels in the first place. The entire row of Charoen Chai shophouses, for example, are owned by Chumbot Pantip Foundation, a foundation of a grandchild of King Rama V. Similarly, across the street, the Plaeng Nam neighborhood is owned by the Crown Property Bureau (which is preparing redevelopment plans there too). The Chumbot Pantip Foundation has terminated its leases, allowing tenants to rent on a month-by-month basis that requires them to move out upon receiving notice. Failure to do so would result in a fine, per day, of one month's rent. To make matters worse, Charoen Chai neighborhood is tucked

11 These comments were raised during the panel discussion Yankao lao krung: thima thipai lae kwamplianplaeng kong yan tangtang nai krungthep tungtae adit tueng pachuban [Old districts recount stories: backgrounds and change in Bangkok's old districts from past to present], Bangkok, 9 April 2014.

12 Ibid

13 บะหมี่จับกับ (bami chapkang) in Thai. 
between two metro stations located 700 meters apart. One resident suggests that 'everything here [in between the two stations] is evictable', circling her finger around Charoen Chai's location on the map (see Figure 3). ${ }^{14}$

Let me share a few other examples that refute technical objectivity. In one public forum, one attendee dismissed altogether the objective basis of the TOD density zoning, arguing that the metro and the TOD zoning are not naturally a catalyst for demolition..$^{15}$ Instead, he questioned the role of human choice in producing what is otherwise passed as a technical calculation. The decision to increase density, he argues, descended directly from the 'vision of the people who laid out the actual plan' and 'it is ultimately up to those people whether they see this area as a preservation area or a cultural space or not. It has little to do with the metro'. In fact, there are at least five counterarguments against objectivity. First, in one of my interviews, a senior planner confirmed the role of human decision in the deliberation process of the Chinatown planning motions. As a rule, the zoning provisions are intended to be, he reveals, a 'comprehensive plan for the entire city'. Therefore, where there is a metro station, the TOD zoning would follow as an automatic condition. An exemption for the Chinatown station, he adds, is technically possible, but it would constitute an 'exception, thus violating the standards'. Second, when I asked about the rationale behind the specific figure of 500 meters (as opposed to, say, 400 or 600, or 450 or 550 meters, or any other imaginable figure), two planners both claimed this distance to be an international standard used by major cities in the world. Third, they admitted, however, that realestate parties had submitted requests for a radius as large as 1,000 meters. Fourth, the planners also added that, given Bangkok's tropical climate, a shorter radius of perhaps 300 meters would have been more appropriate and 'walkable'. ${ }^{16}$ And fifth, the BMA did make an exception for the historical district, exempting it from the TOD zoning (BMA, 2013: 62-65). My point is that numbers are pliable. Their plasticity can therefore be manipulated. There is little objectivity beyond the round numbers. These various judgments suggest the salient role of subjective human choice, which contradicts the objective claim to 'universal application'.

\section{Encountering a space of difference: a thin category and a careless geometry}

This section tries to conceptualize a space of difference in relation to the problematic universalism of zoning. Chinatown exemplifies a poor fit between simplified bureaucratic containers and the complex thing we call land. It is clear that the subcategorizations C-1, C-2, C-3 represent an important planning novelty for Bangkok, showing planners' heightened sensitivity to a wide variety of economic needs and functions. The planners duly recognize that the 'commercial zone' is not monolithic: not all commercial zones serve the same scales and purposes. However, such recognition remains a functionalist one. As land is viewed as an entity that can and should perform one discretely prescribed function, land is cast as land use. City dwellers are cast as 'producers' and 'users' of goods and services in a particular piece of land.

Within such an impoverished formulation, zoning causes misalignments because it cannot accommodate particularity. First, the C-3 category presents a problem for both space and time. Despite being true for a certain time at a certain place (namely, the prototypical Samyam), it is used to regulate the experience of the central commercial districts everywhere and at all times. Therefore, while the recent zoning maps are sensitive to commercial stratification, they are blind to the multiple particularities of each of the zones, negating their internal variations and subsuming

14 Interview, 30 April 2015.

15 Comments raised at the public forum Rue mueangkao rakngao rao cha yu trong nai [Demolishing the Old Town, where will our historical roots be?], Bangkok, 5 August 2012 
them under a standardized category. Chinatown residents' pleas for a change from 'commercial land use' to 'historic preservation land use' or to 'commercial land use with historic significance' suggest another depth of commercial experience. Secondly, as the zoning map seeks to join zones into a larger order, it ignores the local order. By inserting the zones into the citywide hierarchy of needs, the zoning map decouples the zone from its immediate context, from other aspects of the complex thing we call land. The aforementioned interviews and public forums indicate that residents' contentions point to other land-based claims that are both symbolic (for example, historical identity, values and place attachment) and material (for example, livelihoods and housing security). These claims to space suggest that there are more issues surrounding a zone than its naked function, that there is more to land than land use. Land use is a poor arbiter of land, for the thinness of the former does not provide enough room, technical and ethical, to mediate the complex phenomenon of the latter, which is historically tied to occupational livelihoods, communal cohesion, individual attachments and the general will and right to dwell.

Similarly, the TOD zoning is a result of technical rationalization. It involves a high degree of space-behavior determinism. Despite the unresolved empirical effectiveness of TOD (Cervero et al., 2002; Canepa, 2007) and despite the fact that no prior feasibility studies had been conducted, such hopeful yet naive rationalization led the BMA to approvingly underwrite the TOD zoning. However, the map's blank surface that planners worked with belies the land's more complex urban geography. Intended as a well-meaning intervention, the 500-meter TOD zoning became a careless geometry upon implementation. I use the term 'careless' not in an accusatory but rather in an analytical way. The geometry, I argue, does not care for two conditions of Chinatown: sociospatial forms and housing tenure. First, high density encourages an architectural form that is at odds with the preexisting sociospatial forms. The dense urban form that TOD zoning desires-the string of intensely built nodes along a transit line-contrasts with Chinatown's low-rise rows of shophouses (see Figure 4). There is a worrying contrast between the way in which zoning is administered and the way the neighborhood space of Chinatown is formed. Zoning treats a land parcel as an individual unit of calculable density. It views a discrete building as an appropriate site of intervention. However, the historical emergence of land subdivision in this part of town is collective and mutually constituting, as exemplified by the building typologies and the agglomerate economies.

Second, and more importantly, although TOD claims neutrality in its universal application (which I refuted earlier), not everyone has the same agency to act upon the hoped-for density. The occupant of a residence is not necessarily the owner of the property. In this regard, the TOD zoning fails to see one important aspect of Chinatown: housing tenure. The zoning map assumes an even, equal field of privately held land, but in reality, historical landlord-tenant relations exist. There are deeply entrenched, strategic land interests that are waiting to act upon opportunities. Only around half of Chinatown $(55.31 \%)$ is freehold, owned by a few private individuals. The rest of the area constitutes leasehold from major landowners, for example, the Crown Property Bureau, temples, state agencies and single private individuals (KMITL, 2001: 3-30). The area known as Chinatown was considered undeveloped 'suburban' land in the late eighteenth century. As the land was sparsely populated and thus considered abundant until the late nineteenth century (Ouyyanont and Sajjanand, 2001), past monarchs gave it away quite freely to their princes and princesses and to their aristocrats. Following the trade liberalization in the mid-nineteenth century, these members of the nobility, in turn, leased out their properties to Chinese traders. These historical tenure patterns have persisted to this day. Four major neighborhoods in Chinatown, namely, Woeng Nakhonkhasem, Charoen Chai, Loen Rit and Plaeng Nam, are all owned by these landed 
elites. ${ }^{17}$ Thus, a novel planning intervention that claims to benefit all in fact opens up opportunities only for a certain group of people: the owners of density. Density should therefore not simply be represented by numerical figures or by calculating housing units per land unit. Narrowly conceived, density not only signifies poor understanding of fraught housing tenure relationships, but also serves to justify eviction. An environmentally progressive policy such as urban density, carelessly formulated and hastily executed, ends up producing a socially retrograde effect.

\section{Conclusion}

This article advances two arguments. First, the zoning techniques of land use subcategorization and TOD zoning are formulated through the abstract devices of classification, hierarchization and linear rationalization of cause and effect. Second, limits of such devices are, in turn, exposed when they are imposed upon a space of difference fraught with its own history and contested land tenure. Well-meaning but ill-informed, zoning forgoes histories. It unsees other aspects of land beyond its function and density. My argument is not that land is too complex to be reduced to zones (maybe it is), or that every space is different (maybe it is). Rather, my argument is that such difference is actively unseen under the banner of technical science of urban improvement.

The most worrying concern here is that, despite being a human choice, the functionalist-universalist interpretation wins. The way in which planners dismissed the planning motions submitted by Chinatown residents points to how technical rationality trumps other ways of seeing. The planners' justifications are based on their confined perception of Chinatown's commercial function and its role within the larger city. To view Chinatown as an area of 'commercial land use' is to privilege functional similarity over differences. Similarly, the decision not to exempt Chinatown from TOD zoning is based on upholding the universal application of standards. My purpose here is not to point out what is rhetorically obvious: that the particular will always be different from the universal or vice versa. Rather, my purpose is to highlight the undue weight of zoning in Bangkok (and Thailand). Certainly, high-density zoning in Lower Manhattan caused an uproar in the Chinatown of New York in the 1980s. However, residents there managed to successfully challenge this imposition through various means, such as local groups and court appeals (Lin, 1998: 150-56). By contrast, in Bangkok-a city that lacks appeal mechanisms and that equates planning with zoning-the zoning plan, abstract as it is, is used as the only source of authority, the ultimate truth, and the sole basis on which planners arbitrate dissent.

Universal zoning is often viewed as an urban planning specter of the twentieth century. Chinatown itself has been studied as a site of modernist interventions such as clearance and demolition (Anderson, 1991; Yeoh and Kong, 1994). However, modernist zoning is alive and well as we progress into the twenty-first century to battle new urban imperatives. Sustainability and many related concepts such as resilience and compactness are touted as the goals of contemporary urban planning. The lesson from Bangkok shows that the very means for achieving such a difficult end can be a dangerously facile one. Despite its commendable recognition of new urban problems, the new zoning still remains rigid in character. Modernist city planning in Bangkok does not have at its disposal postmodern planning vocabularies, or the kind of vocabularies that recognize difference. As such, every space in the vast city, including Chinatown, and Little India, for that matter, is filtered through thin grids and careless geometries.

17 Woeng Nakhonkhasem is now owned by TCC Land Company, and Charoen Chai by the Chumbot Pantip Foundation, while Loen Rit and Plaeng Nam are owned by the Crown Property Bureau. 


\section{Napong Tao Rugkhapan, Urban and Regional Planning Program, University of Michigan, 2000 Bonisteel Boulevard, Ann Arbor, Michigan 48109-2069, USA, nrugkh@umich.edu}

\section{References}

Anderson, K.J. (1987) The idea of Chinatown: the power of place and institutional practice in the making of a racial category. Annals of the Association of American Geographers 77.4, 580-98.

Anderson, K.J. (1991) Vancouver's Chinatown: racial discourse in Canada, 1875-1980. McGill-Queen's University Press, Montréal, Canada

BMA (1992) Bangkok comprehensive plan. Bangkok Metropolitan Administration, Bangkok.

BMA (1999) Bangkok comprehensive plan. Bangkok Metropolitan Administration, Bangkok.

BMA (2005) Planning standards. Bangkok Metropolitan Administration, Bangkok.

BMA (2006) Bangkok comprehensive plan. Bangkok Metropolitan Administration, Bangkok.

BMA (2013) Bangkok comprehensive plan. Bangkok Metropolitan Administration, Bangkok.

BMA (2014a) Bangkok statistics of 2014. Bangkok Metropolitan Administration, Bangkok.

BMA (2014b) Comprehensive plan implementation guidelines. Bangkok Metropolitan Administration, Bangkok.

Canepa, B. (2007) Bursting the bubble: determining the transit-oriented development's walkable limits. Transportation Research Record: Journal of the Transportation Research Board 1992.1, 28-34.

Cervero, R., C. Ferrell and S. Murphy (2002) Transit-oriented development and joint development in the United States: a literature review. TCRP Research Results Digest 52.

CCRG (Charoen Chai Conservation and Rehabilitation Group) (n.d.) Charoen Chai: historic district of Charoen Krung cultural heritage. CCRG, Bangkok.

Crampton, J.W. and S. Elden (2006) Space, politics, calculation: an introduction. Social and Cultural Geography Special Issue 7.5, 681-87.

Ellin, N. (1999) Postmodern urbanism. Princeton Architectural Press, Princeton, NJ.

Fainstein, S.S. (2005) Cities and diversity: should we want it? Can we plan for it? Urban Affairs Review 41.1, 3-19.

Ghertner, D.A. (2014) India's urban revolution: geographies of displacement beyond gentrification. Environment and Planning A 46.7, 1554-71.

Holston, J. (1989) The modernist city: an anthropological critique of Brasilia. University of Chicago Press, Chicago, IL.

Huxley, M. (2006) Spatial rationalities: order, environment, evolution and government. Social \& Cultural Geography 7.5, 771-87.

Jackson, J.C. (1975) The Chinatowns of Southeast Asia: traditional components of the city's central area. Pacific Viewpoint 16.1, 45-77.

KMITL (King Mongkut Institute of Technology Ladkrabang) (2001) Final report: specific planning project for Samphanthawong District. Bangkok.
Leffers, D. and P. Ballamingie (2013) Governmentality, environmental subjectivity, and urban intensification. Local Environment 18.2, 134-51.

Legg, S. (2006) Governmentality, congestion and calculation in colonial Delhi. Social \& Cultural Geography 7.5, 709-29.

Legg, S. (2007) Spaces of colonialism: Delhi's urban governmentalities. Blackwell, Oxford and Malden, MA.

Lin, J. (1998) Reconstructing Chinatown: ethnic enclaves and global change. Volume 2, University of Minnesota Press, Minneapolis, MN.

Marshall, S. (ed.) (2012) Urban coding and planning Routledge, Abingdon.

Mitchell, T. (2002) Rule of experts: Egypt, techno-politics, modernity. University of California Press, Berkeley, CA.

Motion Compilation Book (2012) Bangkok Metropolitan Administration, Bangkok.

Nōngnō i Saksī (1991) Ongprakō p thāng kāiyaphāp Krung Rattanakōsin. Phim khrang thī 1 [Bangkok: physical elements of Rattanakosin City]. First edition, Bangkok.

Ouyyanont, P. and S. Sajjanant (2001) Report: an economic history of wage formation and labor market in Thailand, 1930-1995. National Research Council of Thailand, Bangkok.

Pimonsathean, Y. (2009) Heritage buildings on northern Charoen Krung Road. ICOMOS Thai, Bangkok.

Scott, J.C. (1998) Seeing like a state: how certain schemes to improve the human condition have failed. Yale University Press, New Haven, CT.

Scott, D. (2003) 'Creative destruction': early modernist planning in the South Durban Industrial Zone, South Africa. Journal of Southern African Studies 29.1, 235-59.

Sirikulchayanont, P. (2009) Chinese settlement in Thailand: form, character, and cultural influence. $\mathrm{PhD}$ dissertation, Program of Architectural Heritage Management and Tourism, Silpakorn University, Bangkok.

Skinner, G.W. (1957) Chinese society in Thailand: an analytical history. Cornell University Press, Ithaca, NY

Talen, E. (2012) City rules: how regulations affect urban form. Island Press, Washington, DC.

TURCI (Thammasat University Research and Consultancy Institute) (2015) Eighth progress report: planning recommendations for Rattanakosin City's eastern extension areas. Thammasat University, Bangkok.

Watson, V. (2009a) 'The planned city sweeps the poor away ...': urban planning and 21 st-century urbanisation. Progress in Planning 72.3, 151-93.

Watson, V. (2009b) Seeing from the South: refocusing urban planning on the globe's central urban issues. Urban Studies 46.11, 2259-75

Yeoh, B.S. and L. Kong (1994) Reading landscape meanings: state constructions and lived experiences in Singapore's Chinatown. Habitat International 18.4 17-35. 